\title{
Analisa Metode Dua Polinomial untuk Penekanan Sidelobe
}

\author{
Andi Yahya Lubis, Eko Setijadi, Puji Handayani \\ Departemen Teknik Elektro, Fakultas Teknik Elektro, Institut Teknologi Sepuluh Nopember (ITS) \\ email: ekoset@ee.its.ac.id,puji@ee.its.ac.id
}

\begin{abstract}
Abstrak -Dalam radar, antena array sangat umum digunakan karena memiliki nilai gain yang besar dan semakin banyaknya elemen yang digunakan nilai puncak sidelobe yang dihasilkan semakin rendah. Namun jumlah sidelobe akan semakin banyak dan sistem akan semakin kompleks. Untuk membatasi jumlah elemen, diperlukan metode yang menghasilkan nilai puncak sidelobe yang rendah. Metode sidelobe suppression (SLS) dengan teknik dua polinomial merupakan metode penekanan nilai sidelobe dengan cara mengalikan dua faktor array. Dengan jumlah elemen dan null yang ditentukan, pola radiasi yang didapat pada polinomial pertama digunakan untuk mencari posisi null kanan dan kiri yang berdekatan dengan mainlobe. Daerah diluar null tersebut dimanfaatkan untuk wilayah sidelobe serta digunakan untuk mencari weight dari polinomial kedua yang ditujukan untuk penekanan sidelobe. Dalam penelitian ini, metode dua polinomial dibuat berdasarkan rumus dan masukan data yang diberikan pada literatur penelitian Zafar-Ullah, Aqdas dan Fahad yang berjudul "Efficient Sidelobe Suppression by Matching Beam in Two Polynomial Technique". Hasil simulasi kemudian dibandingkan dengan pola radiasi antena array uniform linier dengan 9 elemen dan jarak antar elemennya sebesar $\lambda / 2$. Berdasarkan hasil simulasi, puncak sidelobe level (PSLL) yang dihasilkan pada antena array dengan metode dua polinomial sebesar $-\mathbf{2 1 , 0 7} \mathrm{dB}$ dan lebih rendah dibandingkan dengan PSLL pada antena array tanpa metode yaitu sebesar $11,92 \mathrm{~dB}$.
\end{abstract}

Kata Kunci-array factor, adaptive beamforming, null steering, sidelobe suppression, uniform linear array.

\section{PENDAHULUAN}

$\mathrm{D}$ ALAM radar, antenna array sangat umum digunakan karena keunggulannya seperti memiliki nilai gain yang besar dan bagus dalam menerima sinyal yang datang pada sudut 90 derajat atau tergolong memiliki pola radiasi directional. Namun antena array memiliki kelemahan yaitu semakin banyak antena yang disusun semakin banyak sidelobe yang dihasilkan dan lebar main lobe akan semakin kecil. Hal ini sangat merugikan sebab pada sinyal, main lobe merupakan lobe radiasi yang memiliki informasi utama sedangkan sidelobe merupakan lobe radiasi yang bocor dalam pola radiasi directional sehingga sidelobe juga memiliki informasi yang ada pada main lobe. Akibatnya jika ada perangkat atau antenna terdekat dengan sidelobe akan terjadi inteferensi pada kanalnya. Oleh karena itu diperlukan metode untuk menekan sidelobe hasil dari antena array terutama dalam hal mendesain struktur antena.

\section{URAIAN PENELITIAN}

Pada beberapa penelitian ada yang menggunakan beberapa tahapan dalam menekan sidelobe . Seperti pada penelitian Vinod dan Ajit, "Grating lobe and Suppression using MultiObjective Optimization Techniques [1] " dimana mereka menggunakan SFPT untuk mendapatkan sinyal LFM kemudian hasilnya akan dikelola untuk menekan sidelobe dengan memakai algoritma Multiple-Objective Optimization. Pada penelitian lain yang dilakukan oleh Shafqat, Ijaz ,Fawad dan Aqdas dalam "Null Placement and Sidelove Suppression in Failed Array Using Symetrical Element Failure Technique and Hybrid Heuristic Computation" [2], mereka menggunakan Genetic Algorithm untuk menekan null dan Pattern Search untuk menentukan null mana yang akan ditekan. Contoh lainnya pada penelitian Zafar-Ullah, Aqdas dan Fahad "Efficient Sidelobe Suppression by Matching Beam in Two Polynomial Technique"[3], mereka mengkalikan dua array factor polynomial dimana faktor array yang pertama untuk steering null dan faktor array kedua untuk sidelobe suppression.

Jika dilihat dari kompleksitasnya, penelitian [1][2] lebih rumit dan kompleks dibandingkan dengan penelitian ZafarUllah, Aqdas dan Fahad [3][4] namun tidak banyaknya jurnal yang memanfaatkan metode ini membuat perlu adanya analisa kembali metode tersebut sehingga teruji atau tidaknya metode penekanan sidelobe menggunakan teknik dua polinomial dapat diketahui.

Teknik dua polinomial merupakan optimasi dari teknik polinomial schelkunoff. Didasari pada teori matematis schelkunoff yang menjelaskan bahwa sebuah array linier dengan faktor ruang yang sama dengan hasil dari faktor ruang dua array linier [5]. Sintesis antena merupakan salah satu cara dalam mendesain antena, pada umumnya. Desain dengan cara sintesis yaitu sebuah struktur antena diturunkan untuk memenuhi kriteria karakteristik kinerja yang telah ditetapkan, umumnya seperti pola radiasi (sintesis pola antena). Pada teknik polinomial schelkunoff, desainnya memerlukan informasi mengenai jumlah null dan letaknya. Untuk memperoleh informasi tersebut, didapat melalui jumlah elemen dan koefisien eksitasinya atau Array Factornya. Formulasi Array Factor untuk N-elemen, spasi antar elemen sama, amplitido non-uniform, dan eksitasi fasa progresif dapat dituliskan sebagai berikut: 
Dimana $a_{n}$ adalah eksitasi amplitude nonuniform dari masing-masing elemen. $\mathrm{d}$ adalah jarak antar elemen dan $\beta$ merupakan pergeseran phasa progresif.

Jika

$$
z=x+j y=e^{j \varphi}=e^{j(k d d \cos \theta+\beta)}
$$

Maka AF diubah menjadi:

$$
A F=\sum_{n=1}^{N} a_{n} e^{j(n-1)(k d) \cos \theta+\beta)}=\sum_{n=1}^{N} a_{n} e^{j(n-1) \psi}
$$

yang merupakan sebuah polinomial sudut (N-1). Dari matematika varibel kompleks dan aljabar, semua polynomial sudut (N-1) memiliki akar-akar (N-1) dan dapat dinyatakan sebagai hasil dari (N-1) istilah linear. Sehingga dapat ditulis menjadi:

$$
A F=a_{n}\left(z-z_{1}\right)\left(z-z_{2}\right)\left(z-z_{a}\right) \ldots\left(z-z_{N-1}\right)
$$

dimana $\mathrm{z}_{1}, \mathrm{z}_{2}, \mathrm{z}_{3}, \mathrm{z}_{\mathrm{N}-1}$ adalah akar-akar, yang mungkin kompleks, dari polinomial. Magnitudo dari (3) dapat dinyatakan seperti:

$$
|A F|=\left|a_{n}\right|\left|z-z_{1}\right|\left|z-z_{2}\right|\left|z-z_{a}\right| \ldots\left|z-z_{\mathbb{N}-1}\right|
$$

Variabel kompleks $\mathrm{z}$ pada persamaan diatas dapat ditulis dalam bentuk lain:

$$
\begin{gathered}
z=|z|_{e} \psi=|z| \angle \psi \\
\psi=k d \cos \theta+\beta=\frac{2 \pi}{\lambda} d \cos \theta+\beta
\end{gathered}
$$

Nilai $d, \theta$, atau $\beta$ magnitudo dari $z$ terletak pada sebuah unit lingkaran; namun fasanya tergantung pada $\mathrm{d}, \theta$, dan $\beta$. Pada unit lingkaran terbagi menjadi dua bagian yaitu daerah terlihat, bagian yang dapat direalisasikan, dan daerah tidak terlihat, bagian sisanya. Luas dari daerah terlihat dapat diatur dengan jarak antar elemen dan posisi relatifnya pada lingkaran dengan eksitasi dari element fasa progresif [6].

\section{METODE PENELITIAN}

Terdapat tiga tahapan utama pada metode dua polinomial yaitu yang pertama adalah mencari faktor array pertama, mencari faktor array kedua dan mengkalikan kedua faktor array tersebut.

Faktor array pertama dapat dicari dengan metode polynomial schelkunoff dan jika diasumsikan sebuah array uniform linier (ULA) dengan $\mathrm{N}$ elemen omnidirectional dengan jarak antar elemen $d$ dan pergeseran fase progresif $\alpha$. sudut datang $\theta$ dari gelombang datar yang mengenai array dan perbedaan jalur gelombang dari gelombang tersebut pada elemen yang berdekatan dirumuskan $\mathrm{x}=\mathrm{d} \cos \theta$ sesuai dengan gambar 1.
Keluaran dari elemen-elemen array akan ditambakan setelah dikalikan dengan beban yang sudah dipilih secara tepat $A_{0}, A_{1}, \ldots, A_{N-1}$ untuk mengatur null pada arah jammer .

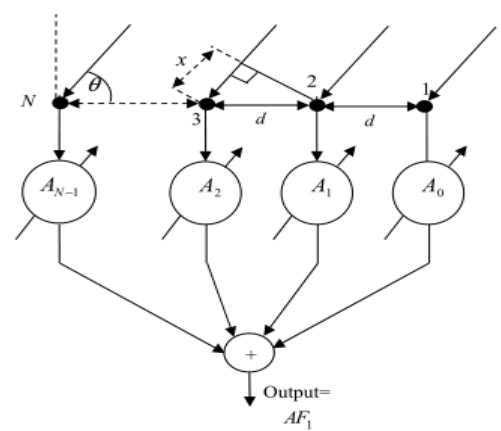

Gambar 1. Sebuah N elemen ULA dengan N-1 null yang dapat diatur

Pada Gambar 1 seluruh elemen pada array dijadikan sebagai referensi dan perbedaan fasa sinyal yang diterima pada elemen dituliskan dengan rumus:

$$
\Psi=a+\left(\frac{2 \pi}{\lambda}\right) d \cos (\theta)
$$

dimana $2 \pi / \lambda=\mathrm{k}$ merupakan jumlah gelombang. Pergeseran fasa progresif $\alpha$ akan mengatur arah main lobe sesuai yang diinginkan. Ditunjukkan pada persamaan sebelumnya :

$$
\alpha=-\left(\frac{2 \pi}{\lambda}\right) d \cos \left(\theta_{s}\right)
$$

Jika $\mathrm{z}=e^{j \psi}$, maka faktor array pertama dapat dinyatakan sama dengan

$$
A F=\sum_{n=1}^{N} a_{n} z^{n-1}=a_{1}+a_{2} z+a_{a} z^{2}+\cdots+a_{N} z^{N-1}
$$

Faktor array kedua merupakan penekanan sidelobe dan dapat dinyatakan dengan rumus:

$$
\mathrm{AF}_{2}=b_{0}+b_{1} Z+\cdots+b_{N 2-1} z^{N_{2}-1}=\mathbf{s}_{N 2} \mathbf{b}
$$

dimana $b=\left[b_{0}, b_{1}, \ldots, b_{\mathbb{N}_{2}-1}\right]^{T}$ adalah vector beban kompleks dan $s_{\mathrm{N}_{2}}=\left[1, z_{x, m} z^{\mathrm{N}_{2-1}}\right]$ adalah vector steering. Syarat pada vektor $\mathbf{b}$ yaitu menjamin penekanan sidelobe dan mengarahkan main lobe pada arah yang sama dengan faktor array pertama $\left(\mathrm{AF}_{1}\right)$. Untuk mencari vektor $\mathbf{b}$ diperlukan beberapa tahapan yaitu mencari sudut yang dapat menekenan sidelobe $\theta_{i}$, mencari vektor steering $\mathrm{S}_{\mathrm{N} 2}$ dengan sudut $\theta_{i}$ sebagai syarat $\mathbf{b}$.

Untuk mencari sudut yang dapat menekan sidelobe $\theta_{i}$, suatu daerah pengukuran harus ditentukan. Daerah tersebut diasumsikan sebagai $S_{R}$, yaitu gabungan dari dua bagian yang berisi sudut dari daerah sidelobe kiri dan kanan main beam dengan lebar beam $\theta_{m b}$ tertentu.

$S_{R}=\left\{0^{0}<\theta \leq \theta_{s}-\frac{\theta_{\mathrm{mb}}}{2}\right\} \cup\left\{\theta_{s}+\frac{\theta_{\mathrm{mb}}}{2}<\theta \leq 180^{\circ}\right\}$ 
Setelah menentukan banyaknya sampel yang akan diambil, $p$, sudut-sudut yang disampel harus melalui syarat sebagai berikut:

$$
\mathrm{A}_{S \mathrm{SR}}=\left\{\theta_{i} \mid \theta_{i} \in S_{R} \wedge \theta_{i}=\theta_{0}+i \delta \theta\right\} \subseteq S_{R},
$$

dimana $\theta_{0}$ adalah sudut sampel permulaan, i merupakan urutan sampel p- 1 ,dan $\delta \theta$ adalah jarak antar sampel. Sudutsudut hasil sampel pada $\mathrm{A}_{\mathrm{SR}}$ dibuat menjadi vektor steering $\mathrm{S}_{\mathrm{N} 2}$ dan ditaruh pada matriks $\mathbf{A}$ dan dituliskan dengan persamaan:

$$
\mathrm{A}=\left[\mathrm{S}_{N_{2}}\left(\theta_{0}\right) \mathrm{S}_{N_{2}}\left(\theta_{1}\right) \cdots \mathrm{S}_{N_{2}}\left(\theta_{p-1}\right)\right]^{T}
$$

dengan

$$
s_{\mathbb{N}_{2}}\left(\theta_{\mathrm{i}}\right)=\left[1_{3} z_{\mathrm{i}, \ldots,} z_{\mathrm{i}}^{N_{2}-1}\right]
$$

dan

$$
z_{\mathrm{i}}=\exp \left(j \left(\alpha+\left(\frac{2 \pi}{\lambda}\right) d \cos \left(\theta_{i}\right)\right.\right.
$$

Karena tujuan dari $\mathrm{AF}_{2}$ adalah sebagai penekan sidelobe maka daya keluaran array harus diperkecil sepanjang sudut $\theta_{i}$ yang berada pada $A_{S R}$ dengan batasan unit keluaran sepanjang arah main beam yang diinginkan $\theta_{s}$. Hal tersebut dapat dicapai jika puncak daya keluaran dibatasi dalam daerah sidelobe, yaitu sidelobe level tertinggi yang memiliki nilai terkecil. Masalah ini dapat ditulis sebagai berikut:

$$
\begin{aligned}
& \min _{b} \max \left(\left|s_{\mathbb{N}_{2}}\left(\theta_{i}\right) \mathbf{b}\right|\right), \quad \theta_{i} \in \mathrm{A}_{\mathrm{SR}} \\
& \text { subject to } \quad s_{\mathrm{N}_{2}}\left(\theta_{\Omega}\right) \mathbf{b}=\mathbf{1}
\end{aligned}
$$

Minimalisasi daya ini dapat dicari dengan menggunakan second-order cone programming (SOCP) yang merupakan bagian dari optimasi convex. Sehingga menjadi persamaan baru:

$$
\begin{array}{cl}
\text { Minimize } & t \\
\text { subject to } & |\mathbf{A b}| \leq \mathrm{t} \\
& \mathbf{S}_{\mathbf{N} 2}\left(\theta_{s}\right) \mathbf{b}=1
\end{array}
$$

Masalah optimasi ini dapat diselesaikan dengan menggunakan [7] yang merupakan sebuah program matlab bernama cvx program.

Jika vektor beban kompleks b sudah didapat maka faktor array kedua bisa didapat dengan mengkalikan beban dengan vektor steering. Hasil $\mathrm{AF}_{1}$ akan dikalikan $\mathrm{AF}_{2}$ untuk

\begin{tabular}{|c|c|c|c|}
\hline No & Parameter & Jumlah & Keterangan \\
\hline 1 & $\mathrm{~N}_{1}$ & 5 & $\begin{array}{c}\text { Jumlah elemen array linier } \\
\text { pertama }\end{array}$ \\
\hline 2 & $\mathrm{~N}_{2}$ & 5 & $\begin{array}{l}\text { Jumlah elemen array linier } \\
\text { kedua }\end{array}$ \\
\hline 3 & d & $\lambda / 2$ & Jarak antar elemen \\
\hline 4 & $\theta_{\mathrm{s}}$ & $\begin{array}{c}95^{0} \\
20^{0}, 70^{0}\end{array}$ & Arah main beam \\
\hline 5 & $\theta_{1 \mathrm{i}}$ & $\begin{array}{l}, 120^{\circ} \\
, 160^{0}\end{array}$ & Sudut Null \\
\hline 6 & $\theta_{\mathrm{mb}}$ & $\begin{array}{c}30^{0}, 40^{0} \\
50^{0}\end{array}$ & Lebar main beam \\
\hline
\end{tabular}
mendapatkan $\mathrm{AF}$ dengan sidelobe level yang rendah.

\section{PRINSIP-PRINSIP PUBLIKASI}

Untuk mengetahui sesuai atau tidaknya program simulasi yang telah dibuat, faktor array hasil simulasi akan dibandingkan dengan hasil simulasi pada literatur [3]. Dengan parameter berikut:
Tabel 1.

Parameter Simulasi

Hasil yang didapat sesuai dengan hasil simulasi pada literatur. Berikut hasil pada simulasi:

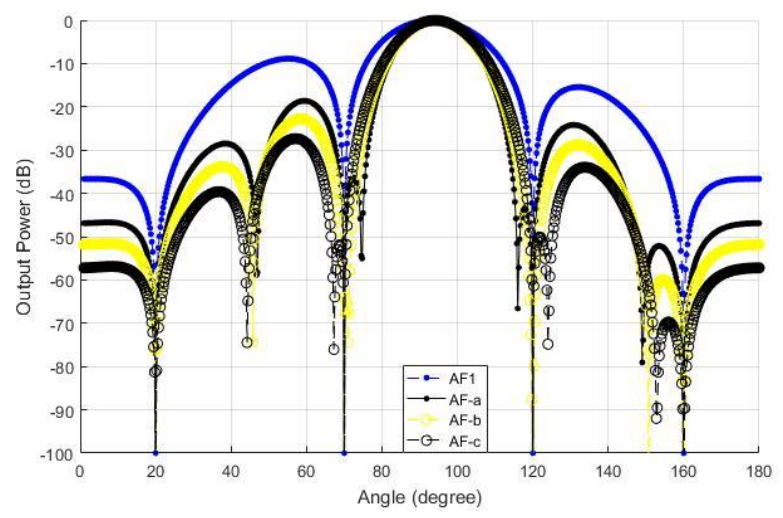

Gambar 2. Hasil Faktor Array pada Simulasi

Selanjutnya nilai faktor array pada simulasi dengan metode akan dibandingkan dengan nilai faktor array simulasi tanpa metode. Hasilnya ditampilkan pada Gambar 3.

Garis biru pada Gambar 3 merupakan hasil faktor array pada antena array 9 elemen yang menggunakan metode dua polinomial. Sedangkan garis merah merupakan hasil faktor array pada antena array 9 elemen tanpa metode.

Pada Gambar 3, puncak sidelobe level (PSLL) yang dihasilkan metode polinomial pada antena array 9 elemen sebesar $-21,07 \mathrm{~dB}$, sedangkan PSLL dari antena array 9 elemen tanpa metode sebesar $-11,92 \mathrm{~dB}$. 


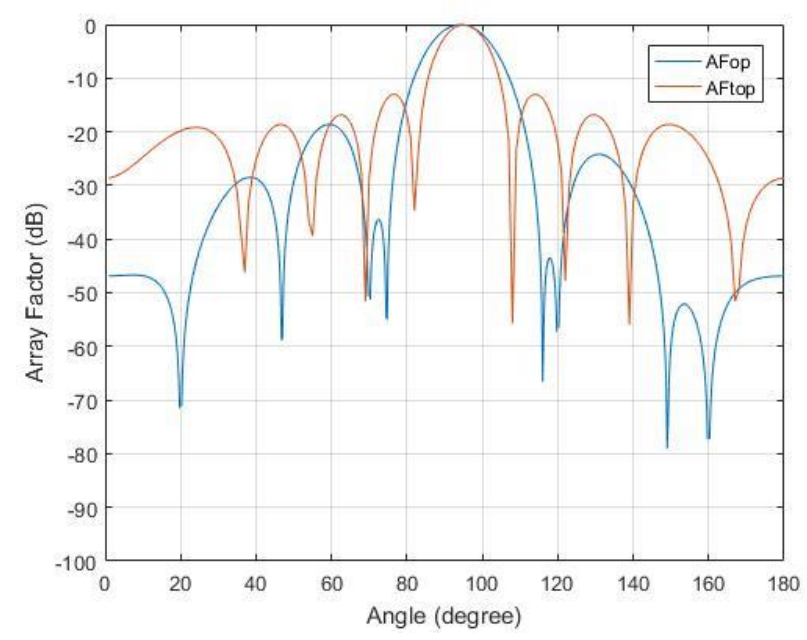

Gambar 3. Hasil Perbandingan Faktor Array antara Metode Dua Polinomial dan Tanpa Metode

Pengujian juga dilakukan dengan merubah-ubah nilai parameter sehingga batasan nilai yang dapat dimasukkan dapat diketahui sesuai dengan perubahan pola radiasi yang ditampilkan dalam simulasi. Contohnya pada perubahan arah main beam dan lebar main beam ditunjukkan pada Gambar 4 dan Gambar 7.

Pada kedua gambar tersebut, garis berwarna magenta merupakan hasil faktor array pada array pertama $\left(\mathrm{AF}_{1}\right)$, garis berwarna hijau,biru, dan hitam putus-putus menggambarkan hasil faktor array pada array kedua. Sedangkan garis berwarna yang sama tanpa putus-putus menggambarkan hasil faktor array pada array keseluruhan. Array keseluruhan merupakan array yang berisi array pertama dan kedua dan faktor array dari array tersebut merupakan pernjumlahan faktor array pertama dan array kedua dalam satuan decibel $(\mathrm{dB})$.

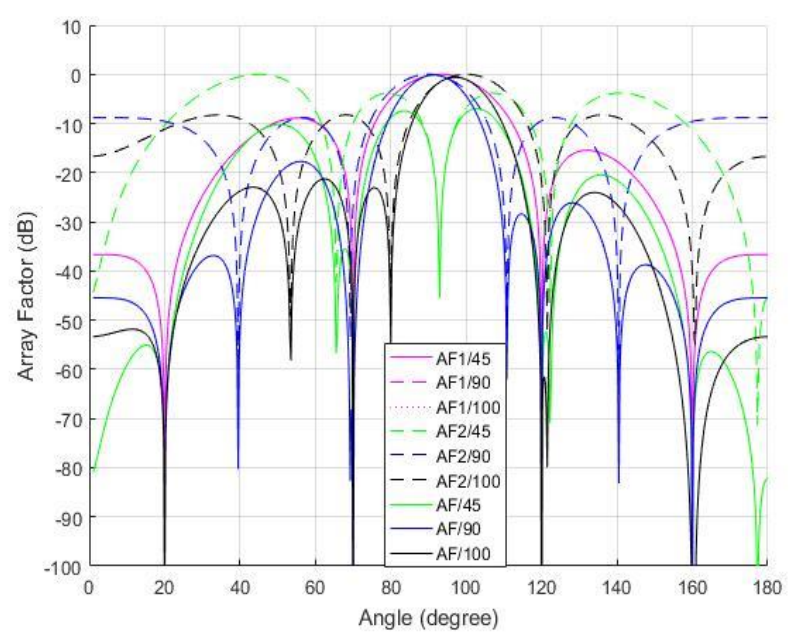

Gambar 4. Hasil Faktor Array pada Perubahan Arah Main Beam $\theta_{s}=45^{\circ}, 90^{\circ}$, dan $100^{\circ}$

Dari hasil simulasi pada perubahan arah main beam $\theta_{\mathrm{s}}=$ $45^{0}$, nilai PSLL dan AF main beam hanya memiliki selisih $0,259 \mathrm{~dB}$. Untuk menyesuaikan arah main beam tersebut, sudut null yang ditentukan diawal perlu diubah sesuai dengan sudut null antena array tanpa metode pada arah main beam yang sama. Sehingga nilai faktor array akan menghasilkan pola yang sama dengan pola radiasi yang diinginkan seperti yang ditunjukkan pada Gambar 5. Dan PSLL yang dihasilkan sebesar -20,74 dB sedangkan PSLL pada antena array tanpa metode dengan elemen yang sama, yaitu 9 elemen, sebesar $12,99 \mathrm{~dB}$.

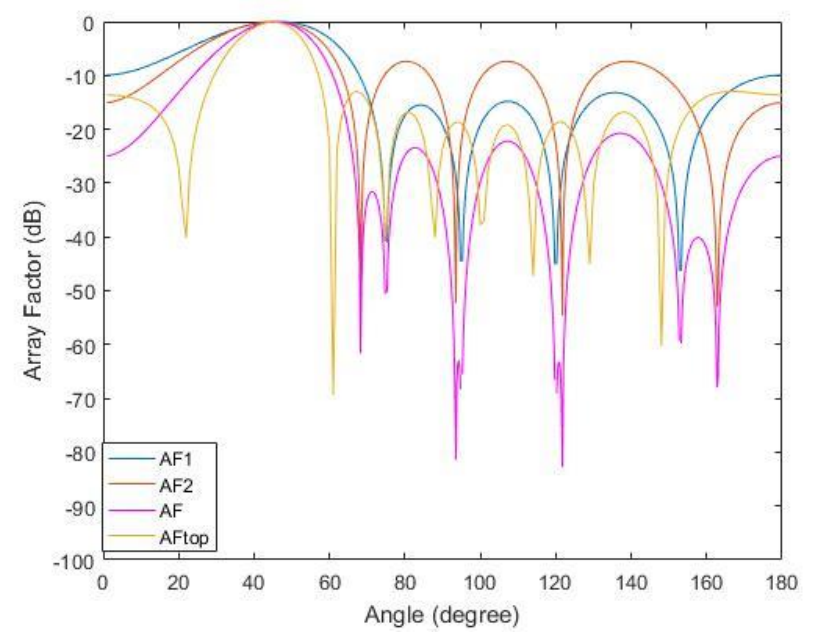

Gambar 5. Hasil Perbandingan antara Metode Dua Polinomial dengan Tanpa Metode pada arah main beam $\theta_{s}=45^{0}$

Perubahan lebar main beam $\theta_{m b}$ akan menyebabkan perubahan pada lebar Half Power Beamwidth (HPBW) namun nilai FNBW akan mencapai maksimum pada batas sudut yang sama dengan sudut null yang ditentukan. Jadi nilai HPBW juga akan mencapai maksimum saat FNBW maksimum. Pada Gambar 6, HPBW saat lebar main beam $90^{\circ}$ sama dengan HPBW saat lebar main beam $100^{\circ}$ (Gambar 6), yaitu sebesar $17,55^{0}$.

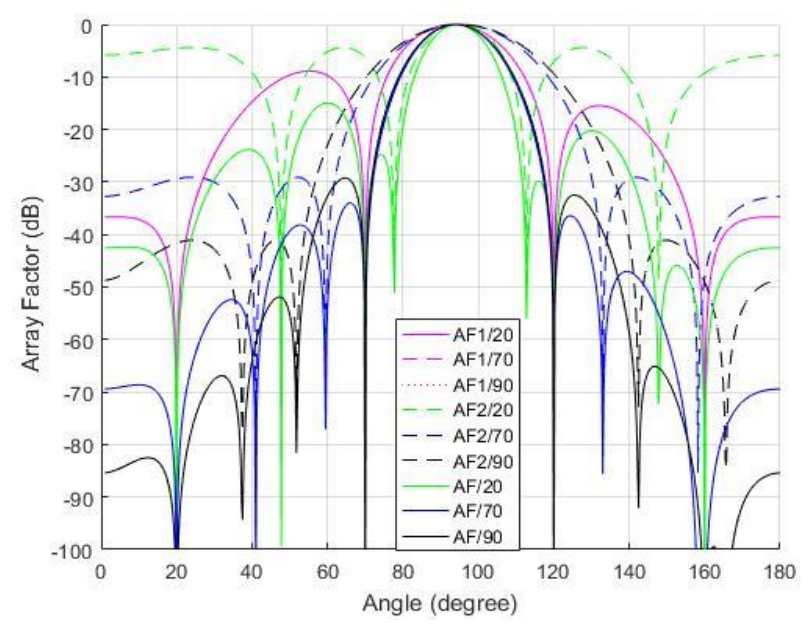

Gambar 6. Hasil Faktor Array pada Perubahan Lebar Main Beam $\theta_{m b}=$ $20^{0}, 70^{\circ}, 90^{\circ}$ 


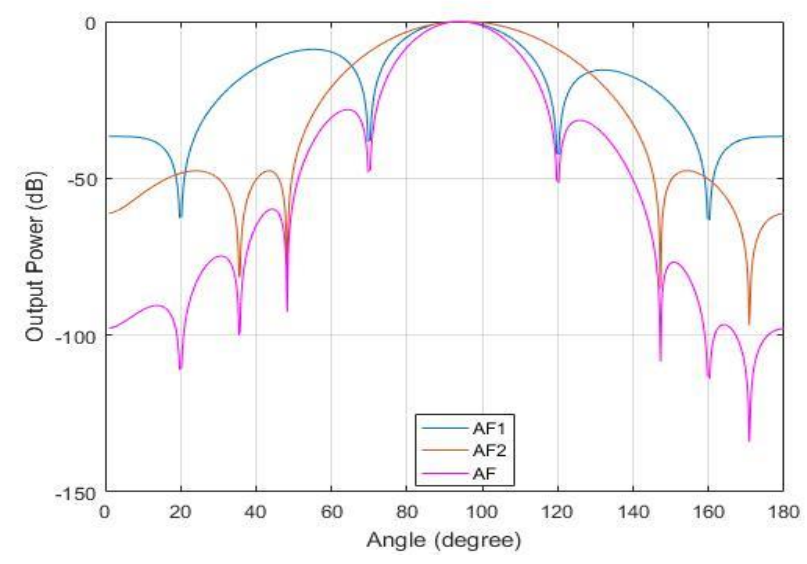

Gambar 7. Hasil Faktor Array pada Perubahan Lebar Main Beam $\theta_{m b}=100^{\circ}$

\section{KESIMPULAN/RINGKASAN}

Berdasarkan hasil simulasi dan setelah dilakukan proses analisa, maka diperoleh kesimpulan bahwa penggunaan metode dua polinomial pada antena array uniform linier 9 elemen dapat menekan sidelobe sebanyak 9,15 dB. Selain itu perubahan arah main beam pada sudut $45^{\circ}$ tidak dapat menghasilkan pola radiasi dengan arah main beam $45^{\circ}$, dan nilai PSLL serta faktor array main beam hanya memiliki selisih 0,259 dB. Untuk menyelesaikan masalah tersebut, sudut null perlu diubah sesuai dengan sudut null pada faktor array tanpa metode. Pada perubahan lebar main beam, nilai HPBW saat lebar main beam $90^{\circ}$ sama dengan HPBW saat lebar main beam $100^{\circ}$, yaitu sebesar $17,55 \mathrm{~dB}$. Hal tersebut didapat jika kondisi sudut null yang diinginkan pada sudut $20^{\circ}, 70^{\circ}, 120^{\circ}$, dan $160^{\circ}$.

\section{UCAPAN TERIMA KASIH}

Penulis AYL mengucapkan terima kasih kepada dosen pembimbing dan dosen-dosen bidang studi telekomunikasi multimedia yang telah memberikan banyak masukan serta arahan sehingga penelitian ini dapat diselesaikan dengan baik.

\section{DAFTAR PUSTAKA}

A. K. S. V. Kumar, "Grating lobe and Sidelobe Suppression using Multi-Objective Optimization Techniques," in IEEE Conference Publication, 2015.

[2] dan A. N. S. U. Khan, I. M. Qureshi, F. Zaman, "Null Placement and Sidelove Suppression in Failed Array Using Symetrical Element Failure Technique and Hybrid Heuristic Computation," Prog. Electromagn. Res. B, vol. 52, pp. 165-184, 2013.

[3] dan F. M. Z.U. Khan, A. Navedd, "Efficient Sidelobe Suppression by Matching Beam in Two Polynomial Techniuque," in Intelligent Systems Engineering (ICISE), 2016.

[4] S. A. H. and A.-R. K. Zafar-Ullah Khan, Aqdas Naveed Malik, Fawad Zaman, "Sidelobe Suppression with Null Steering by Independent weight Control," Int. J. Antennas Propag., p. 6, 2015.

[5] S. A. Schelkunoff, "A mathematical theory of linear arrays," Bell Syst. Tech. J., vol. 22, pp. 80-107, 1943.

[6] W. L. dan G. . T. Stutzman, Antenna Theory and Design Third Edition. Amerika: John Wiley \& Sons, Inc, 2012.

[7] M. G. and S. Boyd, "CVX: a system for disciplined convex programming: cvx version 1.21." 2011. 